\title{
Circulating progenitor cells are increased in newly diagnosed untreated hypertensive patients with arterial stiffening but normal carotid intima-media thickness
}

\author{
Giuseppe Mandraffino ${ }^{1}$, Maria A Sardo ${ }^{1}$, Stefania Riggio ${ }^{1}$, Saverio Loddo ${ }^{2}$, Egidio Imbalzano ${ }^{1}$, \\ Angela Alibrandi ${ }^{3}$, Carlo Saitta ${ }^{1}$, Maurizio Cinquegrani ${ }^{1}$, Enrico M Mormina ${ }^{1}$ and Antonino Saitta ${ }^{1}$
}

Circulating progenitor cells (CPCs), including endothelial progenitor cells (EPCs), have a key role in endothelium repair. Cellular NADPH oxidase (Nox) enzymes, including Nox-containing gp91phox, represent a source of reactive oxygen species (ROS); ROS trigger protective signals but may also have detrimental effects. Cellular defenses against ROS include the enzymes manganese superoxide dismutase (MnSOD), catalase (CAT) and glutathione peroxidase type-1 (GPx-1). We investigated the relationships of CPCs with cellular gp91phox, MnSOD, CAT, GPx-1 and ROS levels and with carotid intima-media thickness (cIMT) and stiffness in hypertensives without additional risk factors for cardiovascular disease. CPCs from 53 newly diagnosed, untreated hypertensives and from 29 controls were isolated and identified by flow cytometry. gp91phox, MnSOD, CAT, and GPx-1 mRNA and protein expression and ROS generation were evaluated in enriched samples of CD34+ cells; cIMT and stiffness were assessed. Hypertensives showed higher arterial stiffness $(P<0.001)$ but no difference in cIMT with respect to controls. ROS generation was slightly increased $(P=0.04)$, whereas gp91phox, MnSOD, CAT and GPx-1 were significantly higher $(P<0.001)$ with respect to controls, as was CPC number $(P<0.001)$, but EPCs were no different. CPC and EPC numbers correlated with gp91phox, ROS and fibrinogen $(\boldsymbol{P}<0.001)$; moreover, gp91phox, MnSOD, CAT and GPx-1 were correlated with CPC number. In early phases of arterial hypertension, before the development of wall thickening and even in the presence of arterial mechanical impairment, CPC number may be increased to maintain an adequate number of EPCs in peripheral blood. Hypertension Research (2011) 34, 876-883; doi:10.1038/hr.2011.56; published online 19 May 2011

Keywords: circulating progenitor cells; antioxidant enzymes; intima-media thickness; arterial stiffness

\section{INTRODUCTION}

Circulating progenitor cells (CPCs), including endothelial progenitor cells (EPCs), have an important role in maintaining endothelial integrity and cardiovascular (CV) homeostasis. ${ }^{1-3}$ Stem cells are mobilized from the bone marrow into the circulation, differentiate into EPCs and home to sites of vascular injury, contributing to the formation of new blood vessels and the repair of injured endothelium. ${ }^{4}$ The impairment of progenitor cell number and function, including differentiation, mobilization and homing, is associated with an increased risk of $\mathrm{CV}$ disease $(\mathrm{CVD}) .^{5-7}$ In particular, $\mathrm{CD} 4^{+}$cells, which are generic progenitors, have a primary role in CVD development or progression over the long term. ${ }^{2}$ In addition, CPC count can help identify patients at higher risk of major adverse CV events. ${ }^{8}$ Thus, it has been suggested that progenitor number and function may mark CVD even better than EPCs alone. $^{6}$ It has, in fact, been suggested that $\mathrm{CD} 34^{+}$ cells are precursors of several CV system cell types, including endothelial, smooth muscular and myocardial cells. ${ }^{2}$ Indeed, circulating $\mathrm{CD}_{3} 4^{+}$cells can rapidly express vascular endothelial growth factor receptor-2 also known as kinase insert domain receptor (KDR) on their surface, becoming EPCs at the site of vascular injury, reflecting the plasticity of these cells and their capacity to respond to vascular stimuli. ${ }^{9}$

The therapeutic administration of autologous EPCs augments neovascularization in vivo ${ }^{10}$ and promotes postinfarction remodeling. ${ }^{11}$ To heal the vascular endothelium and to survive in necrotic and ischemic tissues, EPCs are equipped with an efficacious antioxidant system. Actually, EPCs exhibit a unique robustness against oxidative stress, involving a fine modulation of the expression of antioxidant molecules, including mitochondrial manganese superoxide dismutase (MnSOD) and cytosolic catalase (CAT) and glutathione peroxidase type- $1(\mathrm{GPx}-1) \cdot{ }^{12,13}$ Oxidative stress leads to an imbalance between the pro-oxidant and antioxidant systems, which results in an increased generation of reactive oxygen species (ROS).

\footnotetext{
${ }^{1}$ Department of Internal Medicine and Medical Therapy, University of Messina, Messina, Italy; ${ }^{2}$ Department of Laboratory Medicine, University of Messina, Messina, Italy and 3Department of Statistical Science, University of Messina, Messina, Italy

Correspondence: Professor A Saitta, Department of Internal Medicine, University of Messina, Via Camiciotti, 82, Messina 98123, Italy.

E-mail: asaitta@unime.it
}

Received 1 October 2010; revised 18 February 2011; accepted 19 February 2011; published online 19 May 2011 
Arterial hypertension, a main risk factor for CVD, is associated with endothelial damage and oxidative stress, as well as with an impairment of EPC functions. ${ }^{14-16}$ Thus, in hypertension, increased ROS generation may trigger numerous adverse effects. Physiologically, ROS exert subtle effects on cellular function, acting as regulators of intracellular pathways. ${ }^{15}$ In particular, the coexistence in EPCs of different types of ROS generators with different modalities of activation may result in a sophisticated mechanism of redox signaling that can control the balance among cell growth, proliferation and differentiation. ${ }^{17,18}$

The $\mathrm{NADP}^{+}-$Noxs, multisubunit membrane-associated enzymes that catalyze the one-electron reduction of oxygen using $\mathrm{NADH}$ or $\mathrm{NADPH}$ as the electron donor represent an important source of ROS for EPCs. ${ }^{18,19}$ The Noxs, including the isoform containing the gp91phox or Nox2 isoform, are sensitively modulated by a wide range of factors, ${ }^{20,21}$ including angiotensin-II (AngII), ${ }^{21}$ the main effector of the renin-Ang system, which modulates vascular functions and arterial pressure. AngII seems to accelerate the onset of senescence in EPCs isolated from healthy individuals via stimulation of gp91phox expression and ROS production. ${ }^{22}$ Moreover, EPCs from patients with essential hypertension show an accelerated aging process. ${ }^{23}$ In addition, treatment with AngII receptor blocker or angiotensin converting enzyme (ACE) inhibitor significantly inhibits the increased expression of Nox components and improves the impaired function of EPCs. ${ }^{24,25}$ These findings could indicate a role for NADPH-containing gp91phox in EPCs and arterial hypertension. ${ }^{26}$

The aim of the present study was to investigate the relationship among circulating progenitors, cellular gp91phox expression and ROS generation in newly diagnosed, untreated hypertensive individuals with no additional risk factors for atherosclerosis or CVD. We also evaluated the expression of gp91phox, MnSOD, CAT and GPx-1, ROS generation, and cell counts in relation to arterial stiffness.

We showed that in spite of the increases of gp91phox expression and ROS generation in progenitor cells, the number of CPCs and EPCs was not reduced.

\section{MATERIALS AND METHODS}

\section{Subjects}

We examined 53 untreated essential hypertensive patients (36 men and 17 women, mean age $32.2 \pm 11.0$ years) and 29 normotensive controls matched for sex and age. All hypertensives were newly diagnosed outpatients, and controls were recruited from hospital personnel. Written informed consent was obtained from all subjects, and the study was approved by the Ethics Committee of the University of Messina.

The blood samples were collected at the time of diagnosis; none of the patients or controls were taking any medication; the female subjects were not receiving hormone-based contraceptive therapy. Anti-hypertensive therapy was started after blood collection and instrumental examination. Blood pressure (BP) was measured after $15 \mathrm{~min}$ of quiet rest in the supported right arm of the seated subjects by a validated digital oscillometric device, Omron 705 IT (HEM-759-E) (Omron Healthcare, Kyoto, Japan). ${ }^{27}$ Three measurements performed at intervals of more than 2 min were averaged.

Only subjects with systolic BP (SBP) $\geqslant 140 \mathrm{~mm} \mathrm{Hg}$ and/or diastolic BP (DBP) $\geqslant 90 \mathrm{~mm} \mathrm{Hg}$ were included in the study. Patients with secondary hypertension, body mass index $\geqslant 30$, smoking habit, alcohol consumption, abnormal electrocardiographic and echocardiographic patterns, clinical history of CVD, diabetes mellitus, total cholesterol $\geqslant 6 \mathrm{mmoll}^{-1}$, triglycerides $\geqslant 2.5 \mathrm{mmoll}^{-1}$, or thyroid, liver, or kidney disease were excluded.

All chemical analyses, including cell isolation, were performed on a venous blood sample at the medical center after overnight fasting. Total cholesterol, triglyceride, glucose and fibrinogen were measured by routine methods. Highdensity lipoprotein cholesterol was measured after precipitation of the Apo B-containing lipoproteins with magnesium phosphotungstate. Low-density lipoprotein cholesterol was measured using the Friedewald formula.

\section{Measurement of carotid intima-media thickness (cIMT) and arterial stiffness}

Carotid echo Doppler scan and arterial stiffness assessment were performed using Aloka ProSound ALPHA 10 (Mitaka-shi, Tokyo, Japan) with a 7-15 MHz linear array transducer.

Semiautomated cIMT was evaluated bilaterally on the far wall in the areas of the common carotid ( $1 \mathrm{~cm}$ proximal to the carotid bulb), the carotid bifurcation $(1 \mathrm{~cm}$ proximal to the flow divider) and the internal carotid artery $(1 \mathrm{~cm}$ distal to the flow divider).

Five arterial stiffness parameters, $\beta$-stiffness index ( $\beta$-index), Young's elastic modulus, arterial compliance, augmentation index and pulse wave velocity (PWV), were measured automatically with 'eTRACKING' software (Aloka Prosound ALPHA 10 ultrasound machine, Tokyo, Japan). An extensive explanation of the mechanical and physical bases of this analysis was previously provided. ${ }^{28}$

\section{Flow-cytometric evaluation}

Fresh blood flow cytometry was used (FACSCalibur; Becton Dickinson, Franklin Lakes, NJ, USA) to identify and count progenitor cell subsets. Circulating cells that expressed the stem cell antigens CD34, CD133 and CD34/CD133, but that lacked the endothelial lineage marker KDR were defined as generic CPCs, whereas $\mathrm{CD} 34^{+} / \mathrm{KDR}^{+}$and $\mathrm{CD} 133^{+} / \mathrm{KDR}^{+}$cells were identified as EPCs. ${ }^{29}$

The cells were analyzed for the expression of surface antigens with direct three-color flow-cytometry analysis using fluorescein isothiocyanate-, phycoerythrin- and allophycocyanine-conjugated monoclonal antibodies (mAbs), as reported elsewhere. ${ }^{30}$ Staining and analysis were performed using the International Society of Hematotherapy and Graft Engineering guidelines. All peripheral blood samples were collected and stored in $0.34 \mathrm{~m}$ K3EDTA anticoagulant and analyzed within $2 \mathrm{~h}$. A volume of $50 \mu \mathrm{l}$ of peripheral blood was then incubated with $10 \mu \mathrm{l}$ of fluorescein isothiocyanate- or peridinin chlorophyll protein complex (PerCP)-conjugated anti-human CD45 mAb (Becton-Dickinson, BD, San Jose, CA, USA) and with $10 \mu$ l phycoerythrin-conjugated antihuman $\mathrm{CD} 34 \mathrm{mAb}(\mathrm{BD})$ or $5 \mu \mathrm{l}$ of phycoerythrin-conjugated anti-human CD133 mAb (Miltenyi Biotec, Auburn, CA, USA), using the multiparameter flow-cytometric lyse no-wash method PROCOUNT (BD), in a TRUCOUNT tube $(\mathrm{BD})$ with a known number of fluorescent beads. After further incubation with $10 \mu \mathrm{l}$ of allophycocyanine-conjugated anti-human KDR mAb (R \& D Systems, Minneapolis, MN, USA) or with $5 \mu \mathrm{l}$ of anti-human CD133 mAb, double-positive cell phenotypes $\left(\mathrm{CD} 34^{+} / \mathrm{CD} 133^{+}, \mathrm{CD} 34^{+} / \mathrm{KDR}^{+}\right.$and $\mathrm{CD} 133^{+} /$ $\mathrm{KDR}^{+}$) were identified. Incubation was performed at room temperature for 15 min in the dark. 7-Amino-actinomycin D (VIA-PROBE, BD Pharmingen, San Diego, CA, USA) was added to identify viable cells and to exclude dead cells. To avoid cell loss, no wash was performed. Flow-cytometric acquisition and analysis were performed using FACSCalibur (Becton Dickinson); the threshold was set on fluorescein isothiocyanate fluorescence in a dot plot of CD45-fluorescein isothiocyanate vs. side scatter to exclude debris and ensure that all leukocyte populations and microbeads were included. Gating strategies and sample analyses permitted the identification of the different phenotypes. Data were processed using the Macintosh CELLQuest software program (BD).

\section{Expression of MnSOD, GPx-1 and CAT mRNA in circulating $\mathrm{CD}^{+} 4^{+}$cells}

Because $\mathrm{CD} 34^{+}$cells are considered pluripotent stem cells, precursors of myocardial, smooth muscular and endothelial cells, we performed enzymatic assays (mRNA expression, protein levels and activities) on this cell subset. After mononuclear cells were isolated from peripheral venous blood by densitygradient centrifugation, immunomagnetic sorting with the MiniMACS system (Miltenyi Biotec) was employed to enrich the $\mathrm{CD} 34^{+}$cells. $\mathrm{CD} 34^{+}$cell enrichment was validated by flow cytometry, demonstrating that in each sample, more than $95 \%$ of cells expressed CD 34 . The viability of CD $34^{+}$cells was measured by propidium iodide staining and trypan blue exclusion $(98 \%$ of $\mathrm{CD} 34^{+}$cells were viable). Phenotypic characterization of the $\mathrm{CD} 34^{+}$cell suspension, performed by flow cytometry, confirmed that about $95 \%$ of $\mathrm{CD}^{+} 4^{+}$cells coexpressed $\mathrm{CD} 45, \mathrm{CD} 133$ or KDR.

After separation, $\mathrm{CD} 34^{+}$cells $\left(5 \times 10^{5}\right)$ were resuspended in trizol reagent (Invitrogen, Carlsbad, CA, USA). Total RNA was extracted and spectrophotometrically quantified (Biomate 3-Thermo Electron Corporation, Waltham, 
MA, USA). In all, $1 \mu \mathrm{g}$ of total RNA was reverse transcribed using a HighCapacity cDNA Archive Kit (Applied Biosystems, Carlsbad, CA, USA) and random primers, according to the manufacturer's instructions. Total reversetranscribed product $(250 \mathrm{ng}$ ) was used to measure the gene expression of gp91phox, MnSOD, CAT and GPx-1 by real-time PCR. $\beta$-Actin was used as an endogenous control for the final normalization. The reaction for each cDNA metabolite and endogenous control was carried out in the same tube (biplex) using the TaqMan Universal PCR master mix and Assays on Demand ready-touse primers and probes with different reporter dyes (Applied Biosystems). The progression of PCRs was monitored by a 7500 Real Time-PCR System (Applied Biosystems), and the relative expression was calculated by the $2^{-\Delta \Delta C_{t}}$ method. For this method, the average values of gp91phox, MnSOD, CAT and GPx-1 in samples from control subjects were used for calibration ( $1 \mathrm{x}$ sample). The results are expressed as an $n$-fold difference relative to normal controls (relative expression levels). ${ }^{31}$ The nucleotide sequences of some PCR products were confirmed by direct sequencing.

\section{Expression of MnSOD, GPx-1 and CAT protein in circulating $\mathrm{CD}^{+} 4^{+}$cells}

The enzyme levels were measured by western blot. After $\mathrm{CD} 34^{+}$cell enrichment and validation of the phenotype, approximately $1 \times 10^{6}$ cells were lysed with a Cell Extraction Buffer kit (Biosource-Invitrogen) with protease inhibitors added. After centrifugation, the proteins were measured with the DC protein assay kit (Bio-Rad, Hercules, CA, USA). In all, $40 \mu$ g of each protein sample was added to $20 \mu$ l of Laemmli Sample buffer $2 \times$ (Bio-Rad) together with a protein marker (EuroClone, Milan, Italy). After denaturation, each sample and the protein marker were applied to an SDS-12\% polyacrylamide gel. SDS-polyacrylamide gel electrophoresis was carried out at a constant voltage of $160 \mathrm{~V} \mathrm{~cm}^{-2}$ for $3 \mathrm{~h}$. After separation, the proteins were electroblotted on polyvinylidene difluoride (Amersham Biosciences, Piscataway, NJ, USA) overnight at $30 \mathrm{~V}$. The membranes were then treated at room temperature for $1 \mathrm{~h}$ with a $10 \mathrm{~mm}$ Tris, $50 \mathrm{~mm} \mathrm{NaCl}$ buffer, at $\mathrm{pH}$ 7.4, containing $7 \%$ non-fat dry milk and $0.1 \%$ Tween-20. The membrane was incubated for $2 \mathrm{~h}$ at room temperature with the same tris buffered saline/Tween-20 buffer containing $5 \%$ non-fat dry milk and a mouse mAb diluted 1:400. All mouse mAbs were purchased from Santa Cruz Biotechnology (Santa Cruz, CA, USA) (anti-human antibodies: gp91phox, sc-5827; MnSOD, sc-130345; GPx-1, sc-133160; CAT, sc58332). After washes with tris buffered saline/Tween-20 buffer to eliminate excess antibody, the membrane was treated for $1 \mathrm{~h}$ at room temperature with goat anti-mouse IgG- horseradish peroxidase (sc-2005, Santa Cruz Biotechnology) in tris buffered saline/Tween-20 buffer containing 5\% non-fat dry milk. After several washes, the membrane was treated with enhanced chemiluminescent reagents (ECL Prime, Amersham Biosciences) for $5 \mathrm{~min}$, and chemiluminescence was measured by autoradiography on Fuji medical X-ray film (Fujifilm Medical Systems, Stamford, CT, USA). After image acquisition, results were expressed as relative amounts against $\beta$-actin. After stripping each membrane, the $\beta$-actin was revealed under the same conditions by a specific antibody. After normalization, the average gp91phox MnSOD, GPx-1 or CAT concentration in samples from control subjects was considered the calibrator ( $1 \mathrm{x}$ sample), and the results are expressed as an $n$-fold difference relative to normal controls.

\section{Generation of ROS in $\mathrm{CD}_{3} 4^{+}$cells}

ROS generation in $\mathrm{CD}_{3} 4^{+}$cell-enriched samples was assessed using 2,7dichlorofluorescin diacetate. ROS oxidizes 2,7-dichlorofluorescin diacetate, generating a DCF fluorescent compound (2,7-dichlorofluorescein), which is used as an indirect marker of oxidant stress. ${ }^{32}$ DCF is detectable by flow cytometry at wavelengths of 488 (excitation) and $525 \mathrm{~nm}$ (emission). Immediately before the microplate reading, $10 \mu \mathrm{l}$ of the fluorescent probe 2,7dichlorofluorescin diacetate, at a final concentration of $40 \mu \mathrm{M}$, was added to wells containing the cell suspension. ROS formation was monitored measuring $1 \times 10^{4}$ cells per sample for $30 \mathrm{~min}$, with readings every $5 \mathrm{~min}$. Data are expressed as FU (fluorescence intensity relative units).

\section{Statistical methods}

The non-parametric approach was used because variables showed a nonnormal distribution (as verified by the Kolmogorov-Smirnov test), followed by a permutation test-based analysis. ${ }^{33}$ Data are expressed as the mean \pm s.d.. To compare hypertensives with controls, the non-parametric combination test was used. The correlations among the variables were assessed by Spearman's test. A non-parametric stepwise regression analysis was consequently performed. A two-tailed $\alpha$ of 0.05 was used to denote statistical significance.

\section{RESULTS}

\section{Characteristics of subjects}

Table 1 shows the baseline characteristics of the study subjects. Compared with controls, the hypertensives showed higher BP values (SBP: $147.4 \pm 10.7$ vs. $119.5 \pm 14.5$; DBP: $89.1 \pm 11.7$ vs. $67.1 \pm 5.9$; both $P<0.001)$ and higher plasma fibrinogen (319.2 \pm 79.0 vs. $281.1 \pm 50.5, P<0.001)$.

No differences were detected between hypertensives and controls regarding age, body mass index, gender, or plasma glucose, total cholesterol, triglyceride, high-density lipoprotein cholesterol or lowdensity lipoprotein cholesterol.

Table 2 summarizes the vascular parameters: $\beta$-index, augmentation index, PWV and elastic modulus were significantly higher in hypertensives than in controls $(P<0.001)$, but arterial compliance was reduced; However, cIMT was not different between the two groups $(P=$ nonsignificant $)$.

\section{Cell count}

By means of flow cytometry, we identified five different cell subpopulations: $\mathrm{CD}_{4} 4^{+}, \mathrm{CD} 133^{+}, \mathrm{CD} 34^{+} / \mathrm{CD} 133^{+}, \mathrm{CD} 34^{+} / \mathrm{KDR}^{+}$and

Table 1 Characteristics of study population

\begin{tabular}{lcc}
\hline & Controls & Hypertensives \\
\hline Number & 29 & 53 \\
Gender $(\mathrm{m} / \mathrm{f})$ & $16 / 13$ & $36 / 17$ \\
Age $($ years $)$ & $28.7 \pm 6.4$ & $32.2 \pm 11.0$ \\
BMI $\left(\mathrm{kg} \mathrm{m}^{-2}\right)$ & $23.9 \pm 3.4$ & $24.7 \pm 5.2$ \\
SBP $(\mathrm{mm} \mathrm{Hg})$ & $119.5 \pm 14.5$ & $147.4 \pm 10.7^{*}$ \\
DBP $\left(\mathrm{mm} \mathrm{Hg}^{*}\right.$ & $67.1 \pm 5.9$ & $89.1 \pm 11.7^{*}$ \\
TC $\left(\mathrm{mmol} \mathrm{I}^{-1}\right)$ & $4.52 \pm 0.59$ & $4.79 \pm 1.00$ \\
HDL-C $\left(\mathrm{mmol} \mathrm{I}^{-1}\right)$ & $1.36 \pm 0.27$ & $1.30 \pm 0.21$ \\
TG $\left(\mathrm{mmol} \mathrm{I}^{-1}\right)$ & $1.26 \pm 0.25$ & $1.22 \pm 0.30$ \\
LDL-C $\left(\mathrm{mmol} \mathrm{I}^{-1}\right)$ & $2.59 \pm 0.57$ & $2.96 \pm 0.98$ \\
Glucose $\left(\mathrm{mmol} \mathrm{I}^{-1}\right)$ & $4.70 \pm 0.32$ & $4.90 \pm 0.51$ \\
Fibrinogen $\left(\mathrm{mg} \mathrm{dl}^{-1}\right)$ & $281.1 \pm 50.5$ & $319.2 \pm 79.0^{*}$
\end{tabular}

Abbreviations: BMI: body mass index; DBP, diastolic blood pressure; HDL-C, high-density lipoprotein cholesterol; LDL-C, low-density lipoprotein cholesterol; SBP, systolic blood pressure; TC, total cholesterol; TGs, triglycerides.

Values are mean \pm s.d.

${ }^{*} P<0.001$ vs. controls, two-tailed $\alpha$ of 0.05 was used to denote statistical significance.

Table 2 Vascular parameters in hypertensive and control subjects

\begin{tabular}{lcc}
\hline & Controls & Hypertensives \\
\hline Number & 29 & 53 \\
$\beta$-index & $5.33 \pm 1.09$ & $8.67 \pm 2.95^{*}$ \\
Alx $(\%)$ & $-2.82 \pm 3.87$ & $13.56 \pm 16.61^{*}$ \\
PWV $\left(\mathrm{m} \mathrm{s}^{-1}\right)$ & $4.97 \pm 0.35$ & $6.64 \pm 1.31^{*}$ \\
EP $\left(\mathrm{kPa}^{*}\right.$ & $70.4 \pm 8.50$ & $127.4 \pm 54.99^{*}$ \\
AC $\left(\mathrm{mm}^{2} \mathrm{kPa}^{-1}\right)$ & $1.12 \pm 0.26$ & $0.82 \pm 0.32^{*}$ \\
IMT $\left(\mathrm{mm}^{*}\right.$ & $0.77 \pm 0.11$ & $0.82 \pm 0.20$
\end{tabular}

Abbreviations: AC, arterial compliance; Alx, augmentation index; $\beta$-index, $\beta$-stiffness index; EP, Young's elastic modulus; IMT, intima-media thickness; PWV, pulse wave velocity. EP, Young's elastic modul
Values are mean \pm s.d. Values are mean \pm s.d.
${ }^{*} P<0.001$ vs. controls, two-tailed $\alpha$ of 0.05 was used to denote statistical significance. 
Table 3 Measures and percentage of progenitor cell phenotypes

\begin{tabular}{|c|c|c|c|c|c|c|c|c|}
\hline & \multirow{2}{*}{$\begin{array}{c}C D 34^{+} \\
\text {(cells per microliter) }\end{array}$} & \multirow{2}{*}{$\begin{array}{c}C D 133^{+} \\
\text {(cells per microliter) }\end{array}$} & \multicolumn{2}{|c|}{$C D 34^{+} / C D 133^{+}$} & \multicolumn{2}{|r|}{$C D 34^{+} / K D R^{+}$} & \multirow{2}{*}{\multicolumn{2}{|c|}{$\begin{array}{l}C D 133^{+} / K D R^{+} \\
\quad(\text { cells per microliter) }\end{array}$}} \\
\hline & & & $(\%)$ & (cells per microliter) & (\%) & (cells per microliter) & & \\
\hline Hypertensives & $4.16 \pm 2.26$ & $2.97 \pm 1.73$ & 2.16 & $0.09 \pm 0.04$ & 4.81 & $0.20 \pm 0.09$ & 3.36 & $0.10 \pm 0.06$ \\
\hline$P$ & 0.001 & 0.001 & & 0.001 & & NS & & NS \\
\hline
\end{tabular}

Abbreviation: NS, nonsignificant.

Absolute cell count is expressed as mean \pm s.d. (cells per microliter); $C D 34^{+} / \mathrm{CD}_{13} 3^{+}$and $\mathrm{CD} 34^{+} / \mathrm{KDR}^{+}$phenotypes are also expressed as percentage of $\mathrm{CD} 34^{+}$cells; $\mathrm{CD} 133^{+} / \mathrm{KDR}^{+}$as percentage of CD133 ${ }^{+}$cells. $P$, two-tailed $\alpha$ of 0.05 was used to denote statistical significance.

Table 4 Number of CPCs and EPCs

\begin{tabular}{|c|c|c|}
\hline & CPCs (cells/ $\mu l)$ & 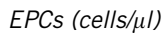 \\
\hline Controls & $4.55 \pm 1.01$ & $0.29 \pm 0.07$ \\
\hline Hypertensives & $7.22 \pm 1.98$ & $0.30 \pm 0.08$ \\
\hline$P$ & 0.001 & NS \\
\hline
\end{tabular}

Abbreviations: CPCs, circulating progenitor cells (CD $34^{+}, \mathrm{CD} / 133^{+}$and $\left.\mathrm{CD} 34^{+} / \mathrm{CD} 133^{+}\right)$; Abbreviations: $\mathrm{CPCs}$, circulating progenitor cells $\left(\mathrm{CD} 34^{+}, \mathrm{CD} / 133^{+}\right.$and $\left.\mathrm{CD} 34^{+} / \mathrm{CD} 133^{+}\right)$; $P$, two-tailed $\alpha$ of 0.05 was used to denote statistical significance. Absolute cell count is expressed as mean \pm s.d. (cells per microliter).

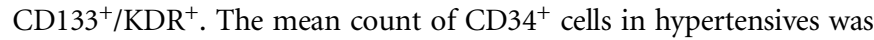
$4.16 \pm 2.26$ cells per microliter and controls had $2.58 \pm 1.04$ cells per microliter $(P<0.001)$; $\mathrm{CD} 133^{+}$cells in hypertensives were $2.97 \pm 1.73$ cells per microliter and in controls they were $1.71 \pm 0.99$ cells per microliter $(P<0.01)$. On average, in control subjects, about $10 \%$ of $\mathrm{CD} 34^{+}$cells also expressed CD133, whereas about $7.5 \%$ of CD $34^{+}$cells from controls also expressed KDR, and about $5.5 \%$ of $\mathrm{CD}_{13} 3^{+}$cells were $\mathrm{KDR}^{+}$. In hypertensive subjects, we found fewer $\mathrm{CD} 34^{+} / \mathrm{CD} 133^{+}$ cells as a total count and percentage $(0.09 \pm 0.04$ cells per microliter, $2 \% ; P<0.0001)$. Compared with controls, in hypertensives, we found no difference in the number of $\mathrm{CD} 34^{+} / \mathrm{KDR}^{+}$or $\mathrm{CD} 133^{+} / \mathrm{KDR}^{+}$cells, although their frequencies were lower (4.81 and 3.36\%, respectively, both $P<0.01)$. In hypertensives, the $\mathrm{CPC}$ number was increased (7.22 \pm 1.98 vs. $4.55 \pm 1.01 ; P<0.001)$, but no difference was found in EPC number with respect to controls $(0.29 \pm 0.06$ vs. $0.29 \pm 0.04$; $P=$ nonsignificant).

The counts and percentages of cell phenotypes are summarized in Table 3; CPC and EPC numbers are shown in Table 4.

Figure 1 shows the flow-cytometry analysis for $\mathrm{CD}^{+} 4^{+} / \mathrm{KDR}^{+}(\mathrm{a})$, $\mathrm{CD} 33^{+} / \mathrm{KDR}^{+}$(b) and $\mathrm{CD} 34^{+} / \mathrm{CD} 33^{+}$(c) phenotypes.

\section{MnSOD, GPx-1, CAT and gp91phox mRNA and protein expression; ROS concentration}

MnSOD mRNA was significantly higher in the enriched sample of $\mathrm{CD} 4^{+}$cells isolated from hypertensives than from controls $(1.71 \pm 0.58$-fold, $P<0.001$ ) (Figure 2a). Likewise, CAT and GPx-1 mRNAs were also increased ( $1.67 \pm 0.52$ - and $1.80 \pm 0.60$-fold, respectively, both $P<0.001$ ) (Figures $2 \mathrm{~b}$ and c). Consistently, MnSOD, CAT and $\mathrm{GPx}-1$ proteins were significantly higher in hypertensives than controls (MnSOD: $2.42 \pm 0.42$-fold; CAT: $2.26 \pm 0.37$-fold; GPx-1: $2.43 \pm 0.50$-fold; $P<0.001)$.

gp91phox mRNA (2.09 \pm 0.32 -fold) and protein levels $(2.86 \pm 0.35$ fold) were higher in hypertensives than in controls (both $P<0.001$ ).

ROS generation was slightly increased in the enriched sample of $\mathrm{CD} 34^{+}$cells from hypertensive subjects compared with controls ( $58.65 \pm 12.26$ vs. $53.48 \pm 7.44 \mathrm{FU}, P=0.04$ ) (Figure 2d).

\section{Relationships among variables}

We found a significant correlation between $\mathrm{CD} 133^{+}$and $\mathrm{CD} 34^{+}$cell counts $\left(r_{\mathrm{s}}=0.672, P<0.001\right)$; CPCs, particularly $\mathrm{CD} 34^{+}$cells, were correlated with gp91phox expression (mRNA: $r_{\mathrm{s}}=0.462, P<0.001$; protein: $0.432, P<0.001)$; $\mathrm{CD} 34^{+}$cells were also correlated with intracellular ROS $\left(r_{\mathrm{s}}=0.227, P<0.05\right)$ and plasma fibrinogen $\left(r_{\mathrm{s}}=0.361, P<0.001\right)$ levels. A positive correlation between CD34 ${ }^{+}$ cell number and PWV was also observed $\left(r_{\mathrm{s}}=0.259, P<0.01\right)$. The linear correlations between $\mathrm{CD} 34^{+}$cell number and gp91phox, plasma fibrinogen, PWV and ROS are shown in Figure 3. gp91phox mRNA expression correlated with intracellular ROS $\left(r_{s}=0.327, P=0.001\right)$, MnSOD $\left(r_{\mathrm{s}}=0.604, P<0.001\right)$, CAT $(0.476, P<0.001)$, GPx-1 $\left(r_{\mathrm{s}}=0.550, P<0.001\right)$ and fibrinogen $\left(r_{\mathrm{s}}=0.252, P=0.01\right)$ levels. Significant correlations were also observed between gp91phox and BP values (SBP: $r_{\mathrm{s}}=0.558, P<0.001$; DBP: $r_{\mathrm{s}}=0.582, P<0.001$ ); moreover, we found that in hypertensives, $\mathrm{PWV}, \beta$-index, augmentation index and elastic modulus correlated with gp91phox mRNA expression $\left(r_{s}=0.623, P<0.001 ; 0.505, P<0.001 ; 0.491, P<0.001 ; 0.602\right.$, $P<0.001$, respectively). Significant correlations between the same parameters and gp91phox protein were also found.

To assess the contribution of each variable to CPC number, a multivariate regression model was estimated, considering biometric parameters, BP, chemical profile, arterial stiffness indices and cell antioxidant enzymes as independent variables. gp91phox proved to be the main factor influencing CPC number (regression coefficient $\beta=0.443, P<0.001)$. A second model, estimated to establish the dependence of gp91phox expression on the other variables, indicated that gp91phox mRNA expression and intracellular protein level were significantly associated with SBP $(0.446, P<0.001)$ and DBP $(0.348$, $P<0.001$ ). Arterial BP (SBP and DBP), as independent variables, influenced the expression of antioxidant enzymes (MnSOD, CAT, GPx-1, all $P<0.001)$.

\section{DISCUSSION}

The main finding of the present study is that the number of CPCs was increased in subjects with essential hypertension and arterial stiffening. Several case-control studies and evaluations in patient series have reported that the number of circulating EPCs is inversely associated with CV risk factors, including hypertension..$^{5-7,14,16}$ The reason why these cells are impaired in patients with risk factors for atherosclerosis has not been well clarified; however, molecules and mediators involved in atherosclerosis and hypertension, including AngII and free radicals, ${ }^{22,23,34,35}$ may have roles. By contrast, others have shown that the decline in the quantity of EPCs is not a constant feature of arterial hypertension. ${ }^{36-38}$ Circulating EPCs were not decreased in previous studies of patients with arterial hypertension and coronary artery disease; ${ }^{36,37}$ a group of patients with CAD with coexisting hypertension had inhibited EPC migration, whereas the absolute number of 
a

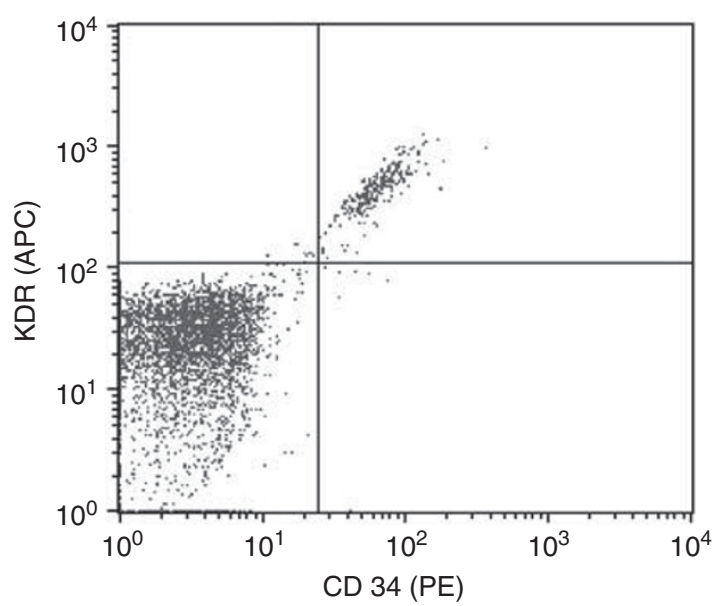

b
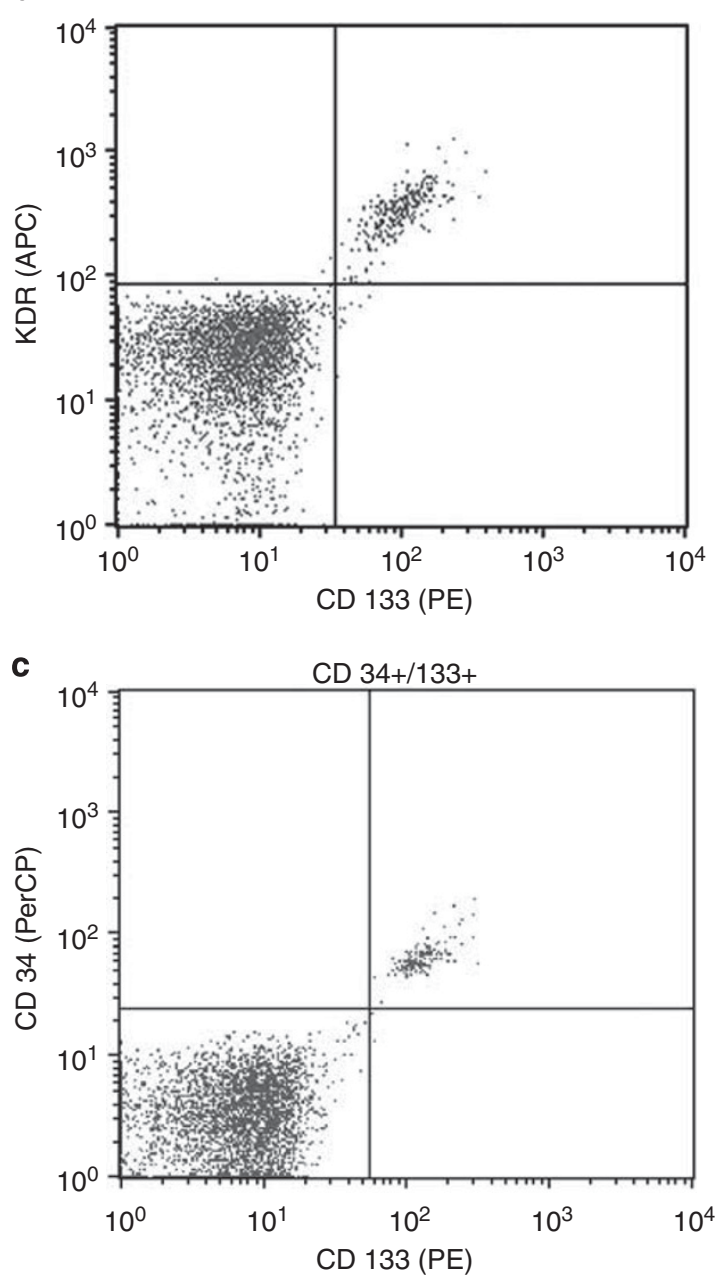

Figure 1 Flow-cytometry analysis for $\mathrm{CD}^{+} 4^{+} / \mathrm{KDR}^{+}$(a), $\mathrm{CD} 133^{+} / \mathrm{KDR}^{+}$(b) and $\mathrm{CD} 34^{+} / \mathrm{CD}_{133^{+}}$(c) phenotypes.

these cells was not altered. Furthermore, Delva et al. ${ }^{38}$, investigated treated hypertensive subjects and reported a normal number of EPCs and no correlation between EPC number and arterial BP values. These discrepancies could be explained by differences in study design, study
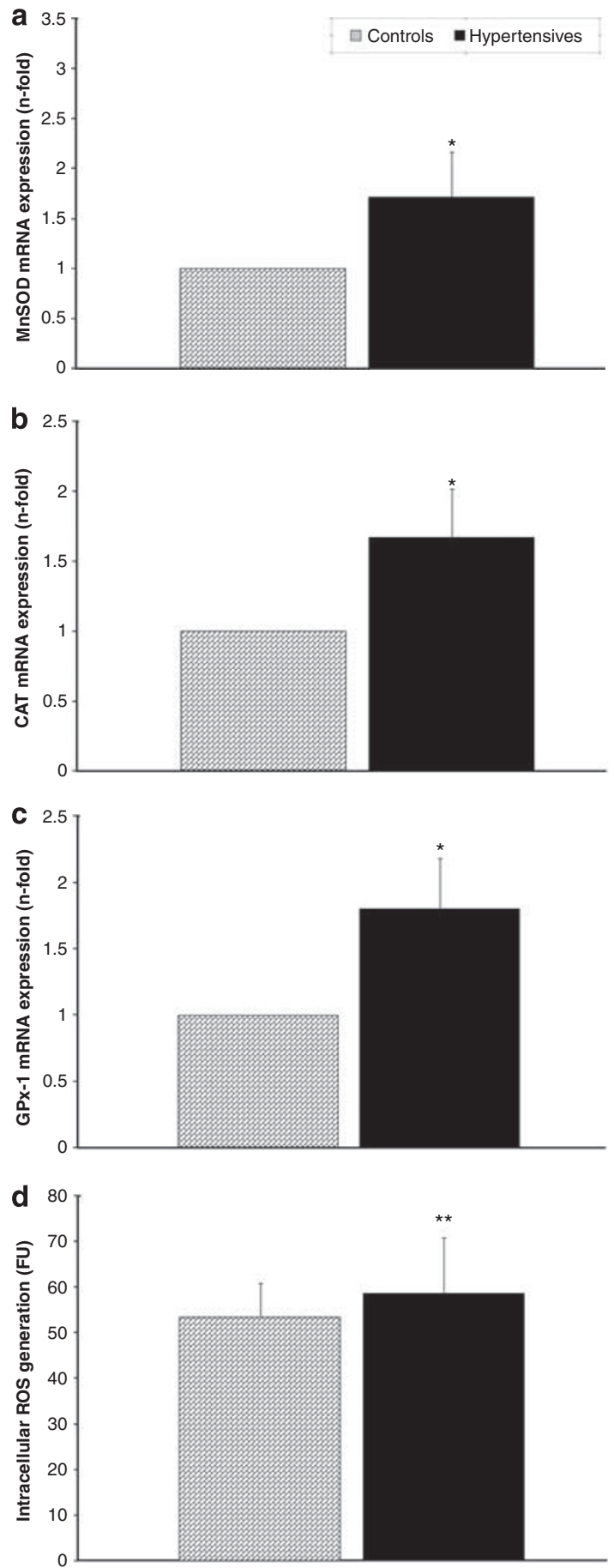

Figure 2 Expression of antioxidant enzymes and production of ROS in circulating progenitor cells. Values are shown as mean \pm s.d. (a) MnSOD, manganese superoxide dismutase; (b) GPx-1, glutathione peroxidase type-1; (c) CAT, catalase; (d) ROS, reactive oxygen species. MnSOD, GPX-1 and CAT mRNA values are expressed as $n$-fold variation vs. control basal mean values. ${ }^{*} P<0.001$ vs. controls; ${ }^{*} P=0.04$ vs. controls.

population and risk-factor burden. Otherwise, because a broad consensus regarding the definition and the antigenic profile of $\mathrm{CV}$ progenitor cells is lacking, ${ }^{6}$ many techniques and methods have been used to identify EPCs, and different cellular phenotypes have been considered in order to 

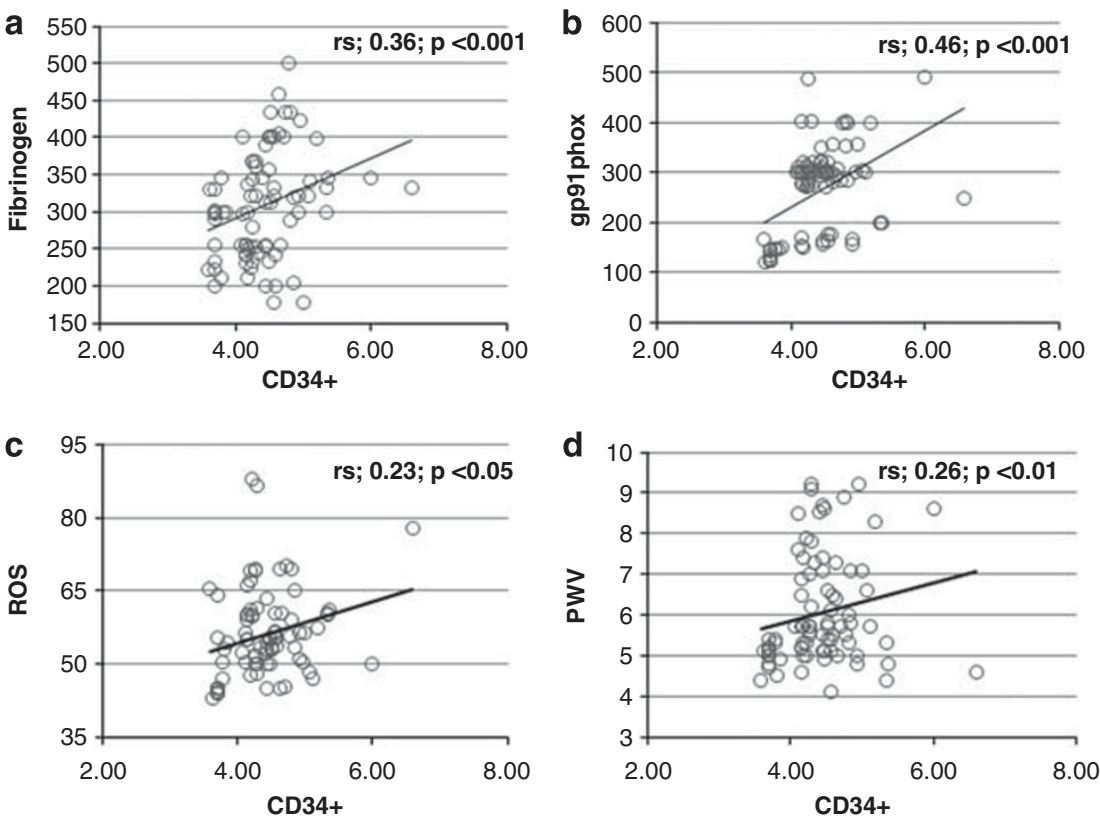

Figure 3 Correlations between CD34 ${ }^{+}$cell number and (a) fibrinogen levels; (b) gp91phox expression; (c) intracellular ROS level; and (d) PWV (pulse wave velocity). $r_{\mathrm{s}}$, Spearman's correlation coefficient; $P$, two-tailed $\alpha$ of 0.05 was used to denote statistical significance.

establish a relationship with risk factors for atherosclerosis. ${ }^{39}$ Accordingly, a straightforward comparison among studies remains difficult.

We used flow cytometry to define cell population expressing CD34, CD133 and KDR surface antigens. Furthermore, our population was homogenous, as hypertensive patients had no additional risk factors for atherosclerosis or signs of CVD. Moreover, none of the patients were taking drugs, as they were newly diagnosed hypertensives. In addition, although electrocardiographic, echocardiographic and carotid echo Doppler examinations did not reveal cardiac alterations or intima-media thickening, hypertensives exhibited impaired relaxation and stiffening of arteries. Because arterial stiffness and IMT are both patterns of early atherosclerosis, alterations in the distension and structure of the arteries may indicate a functional impairment long before the appearance of clinical lesions. Thus, the patients could be considered hypertensives in a precocious phase of vascular involvement. In addition to evaluating the number of CPCs with different antigenic phenotypes, we also measured the expression of antioxidant enzymes in $\mathrm{CD}_{3} 4^{+}$cells.

Different approaches have been proposed to identify circulating endothelial progenitors. Basically, there are two techniques to study EPCs: cell culture and flow cytometry of fresh samples. However, in the strictest sense of defining a cell that displays postnatal vasculogenic activity, a human EPC is a circulating cell that displays the ability to produce endothelial progeny that form endothelial tubes in vitro and contribute to the functional endothelial lining of injured or de novo emergent vascular structures in vivo. To date, the only cells that display this activity at a clonal level are endothelial colony-forming cells. Thus, when defining EPCs by flow cytometry, we have to keep in mind that these cells probably have little in common with cultured EPCs. However, what is apparent in various studies is that EPCs and progenitors, identified by flow cytometry, can provide quantitative data that indicate $\mathrm{CV}$ risk in the setting of atherosclerotic disease. Thus, because the cells expressing surface antigens, such as KDR, CD133, CD34, and any combination of these markers are thought to predict $\mathrm{CV}$ risk and disease, we assessed different combinations of antigens. This approach permits the inclusion of both EPCs and more immature progenitors, such as $\mathrm{CD} 34^{+}$cells. ${ }^{40} \mathrm{CD} 34^{+}$cells are currently considered precursors of several CV system cell types, including endothelial, smooth muscular and myocardial cells. ${ }^{2}$ Additionally, most, if not all, circulating $\mathrm{CD} 34^{+}$cells have the ability to rapidly upregulate KDR expression once activated by peripheral stimuli, becoming EPCs at sites of vascular injury. ${ }^{9}$ Moreover, $\mathrm{CD}_{13} 3^{+}$cells are mainly a subgroup of $\mathrm{CD} 34^{+}$cells, and a close correlation between the expression of these two antigens exists, suggesting that the determination of CD133 expression on $\mathrm{CD}^{+} 4^{+}$cells $\left(\mathrm{CD} 34^{+} /\right.$ $\mathrm{CD}_{133^{+}}$phenotype) would not provide much additional information. ${ }^{6}$ That may explain data from previous studies reporting that the $\mathrm{CD} 4^{+}$cell count is more closely linked to CV risk than double- or triple-positive cells. ${ }^{6,36,37}$ For this reason, we performed enzymatic assays on this cell subset after their enrichment. We found that gp91phox expression and ROS generation were increased in $\mathrm{CD} 34^{+}$ cells, as was MnSOD, CAT and GPx-1 expression. Furthermore, gp91phox was significantly correlated with ROS concentration, progenitor cell number and BP, whereas BP was correlated with gp91phox, PWV, antioxidant enzymes and progenitor cell number.

Evidence suggests that in progenitor cells and EPCs, Nox is a source of ROS, which may be activated by numerous stimuli, including shear stress and AngII. ${ }^{41}$ A correlation among arterial hypertension, gp91phox and ROS has been repeatedly observed, confirming a role for oxidative stress in developing arterial lesions. ${ }^{15}$ Treatment with superoxide dismutase mimetics or antioxidants improves vascular function, regresses vascular remodeling, and reduces $\mathrm{BP} .{ }^{42}$ By contrast, mouse models deficient in ROS-generating enzymes, including NADPH, have lower BP compared with wild-type counterparts, and AngII infusion fails to induce hypertension in these mice. ${ }^{43}$ Furthermore, mice lacking the $g p 91$ phox gene have reduced EPC number and ROS and impaired ischemia-induced blood flow recovery and neovascularization. ${ }^{41}$ This result indicates Nox and ROS are modulators of the recruitment and mobilization of bone marrow-derived cells. Indeed, high levels of ROS are toxic, whereas low levels serve as 
intracellular signaling molecules promoting vascular repair and angiogenesis. ${ }^{15}$ Protection against oxidative stress by ROS is accomplished by a complex defense system composed of several antioxidant enzymes, including MnSOD, CAT and GPx-1, which are able to reduce the damaging potential. ${ }^{12,13}$

Our patients showed alterations in arterial elasticity but not in arterial structure; at this early stage of vascular impairment, increased BP appeared to positively influence gh91phox, antioxidant enzymes and progenitor cell numbers. The upregulation of MnSOD, CAT and GPX-1, in fact, led to a slight increase of ROS in cells from hypertensives $(P=0.04)$ with respect to controls. Thus, our data provide new evidence for a rearrangement of the redox balance in human hypertension with arterial stiffening and no evidence of arterial thickening. ROS metabolism and EPC function appear to be important in hypertension, but we found that in hypertensives, the adjustment of the equilibrium between pro-oxidant and antioxidant systems was associated with an increased number of more immature progenitors. We found that $\mathrm{CD} 34^{+}$cell number was increased in hypertensives, whereas the absolute count of $\mathrm{CD} 34^{+} / \mathrm{KDR}^{+}$cells was similar to control subjects. In terms of cell function, this may represent an adaptive mechanism through which the increased release of bone marrow $\mathrm{CD} 34^{+}$progenitors contributes to maintain the pool of EPCs in peripheral blood, despite increased BP and oxidative stress.

The present study has several limitations. First, we did not evaluate whether changes in the redox system reflected a restorative action on the vascular endothelium, or rather were an expression of increased cell turnover. We did not perform a longitudinal study to understand whether changes in $\mathrm{CD} 34^{+}$cell count were associated with the development of cIMT and lesions. Furthermore, we did not investigate the possibility of accelerated senescence of progenitor cells and EPCs in hypertensives ${ }^{23}$ or the phenotypes of cells and the various other parameters after drug therapy. However, we found a slight increase of intracellular ROS level, rather than a significant enhancement of oxidative stress in cells; moreover, our hypertensives presented an early arterial stiffening but a normal intima-media thickness. Future research should focus on clarifying the processes involved in regulating ROS metabolism and oxidative stress in progenitor cells.

\section{CONFLICT OF INTEREST}

The authors declare no conflict of interest.

\section{ACKNOWLEDGEMENTS}

This work was supported by a grant of the University of Messina (Fondo d'Ateneo PRA 2008). We are grateful to the hospital personnel who agreed to act as control subjects.

1 Urbich C, Dimmeler S. Endothelial progenitor cells: characterization and role in vascular biology. Circ Res 2004; 95: 343-353.

2 Fadini GP, de Kreutzenberg S, Agostini C, Boscaro E, Tiengo A, Dimmeler S, Avogaro A. Low CD34+ cell count and metabolic syndrome synergistically increase the risk of adverse outcomes. Atherosclerosis 2009; 207: 213-219.

3 Steinmetz M, Nickenig G, Werner N. Endothelial-regenerating cells: an expanding universe. Hypertension 2010; 55: 593-599.

4 Asahara T, Murohara T, Sullivan A, Silver M, van der Zee R, Li T, Witzenbichler B, Schatteman G, Isner JM. Isolation of putative progenitor endothelial cells for angiogenesis. Science 1997; 275: 964-967.

5 Schmidt-Lucke C, Rossig L, Fichtlscherer S, Vasa M, Britten M, Kamper U, Dimmeler $\mathrm{S}$, Zeiher AM. Reduced number of circulating endothelial progenitor cells predicts future cardiovascular events: proof of concept for the clinical importance of endogenous vascular repair. Circulation 2005; 111: 2981-2987.

6 Fadini GP, de Kreutzenberg SV, Coracina A, Baesso I, Agostini C, Tiengo A, Avogaro A Circulating CD34+ cells, metabolic syndrome, and cardiovascular risk. Eur Heart $J$ 2006; 27: 2247-2255.
7 Xiao Q, Kiechl S, Patel S, Oberhollenzer F, Weger S, Mayr A, Metzler B, Reindl M, Hu Y, Willeit J, Xu Q. Endothelial progenitor cells, cardiovascular risk factors, cytokine levels and atherosclerosis—results from a large population-based study. PLoS One 2007; 2: e975.

8 Fadini GP, Maruyama S, Ozaki T, Taguchi A, Meigs J, Dimmeler S, Zeiher AM, de Kreutzenberg S, Avogaro A, Nickenig G, Schmidt-Lucke C, Werner N. Circulating progenitor cell count for cardiovascular risk stratification: a pooled analysis. PLOS One 2010; 5: e11488.

9 de Boer H, Hovens M, van Oeveren A, Snoep J, de Koning E, Tamsma J, Huisman M, Rabelink T, van Zonneveld AJ. Human CD34+/KDR+ cells are generated from circulating CD34+ cells after immobilization on activated platelets. Arterioscler Thromb Vasc Biol 2011; 31: 408-415.

10 Shintani S, Murohara T, Ikeda H, Ueno T, Sasaki K, Duan J, Imaizumi T. Augmentation of postnatal neovascularization with autologous bone marrow transplantation. Circulation 2001; 103: 897-903.

11 Assmus B, Schachinger V, Teupe C, Britten M, Lehmann R, Dobert N, Grunwald F, Aicher A, Urbich C, Martin H, Hoelzer D, Dimmeler S, Zeiher AM. Transplantation of progenitor cells and regeneration enhancement in acute myocardial infarction (TOPCARE-AMI). Circulation 2002; 106: 3009-3017.

12 He T, Peterson TE, Holmuhamedov EL, Terzic A, Caplice NM, Oberley LW, Katusic ZS. Human endothelial progenitor cells tolerate oxidative stress due to intrinsically high expression of manganese superoxide dismutase. Arterioscler Thromb Vasc Biol 2004; 24: 2021-2027.

13 Dernbach E, Urbich C, Brandes RP, Hofmann WK, Zeiher AM, Dimmeler S. Antioxidative stress-associated genes in circulating progenitor cells: evidence for enhanced resistance against oxidative stress. Blood 2004; 104: 3591-3597.

14 Ferroni P, Basili S, Paoletti V, Davi G. Endothelial dysfunction and oxidative stress in arterial hypertension. Nutr Metab Cardiovasc Dis 2006; 16: 222-233.

15 Touyz RM. Reactive oxygen species, vascular oxidative stress, and redox signaling in hypertension: what is the clinical significance? Hypertension 2004; 44: 248-252.

16 Pirro M, Schillaci G, Menecali C, Bagaglia F, Paltriccia R, Vaudo G, Mannarino MR, Mannarino E. Reduced number of circulating endothelial progenitors and HOXA9 expression in CD34+ cells of hypertensive patients. J Hypertens 2007; 25: 2093-2099.

17 Piccoli C, D'Aprile A, Ripoli M, Scrima R, Lecce L, Boffoli D, Tabilio A, Capitanio N. Bone-marrow derived hematopoietic stem/progenitor cells express multiple isoforms of NADPH oxidase and produce constitutively reactive oxygen species. Biochem Biophys Res Commun 2007; 353: 965-972.

18 Fan J, Cai H, Tan WS. Role of the plasma membrane ROS-generating NADPH oxidase in CD34+ progenitor cells preservation by hypoxia. J Biotechnol 2007; 130: 455-462.

19 Ushio-Fukai M, Tang Y, Fukai T, Dikalov SI, Ma Y, Fujimoto M, Quinn MT, Pagano PJ, Johnson C, Alexander RW. Novel role of gp91(phox)-containing NAD(P)H oxidase in vascular endothelial growth factor-induced signaling and angiogenesis. Circ Res 2002; 91: 1160-1167.

20 Hwang J, Ing MH, Salazar A, Lassegue B, Griendling K, Navab M, Sevanian A, Hsiai TK. Pulsatile versus oscillatory shear stress regulates NADPH oxidase subunit expression: implication for native LDL oxidation. Circ Res 2003; 93: 1225-1232.

21 Mollnau H, Wendt M, Szocs K, Lassegue B, Schulz E, Oelze M, Li H, Bodenschatz M, August M, Kleschyov AL, Tsilimingas N, Walter U, Forstermann U, Meinertz T, Griendling K, Munzel T. Effects of angiotensin II infusion on the expression and function of NAD(P)H oxidase and components of nitric oxide/cGMP signaling. Circ Res 2002; 90: E58-E65.

22 Imanishi T, Hano T, Nishio I. Angiotensin II accelerates endothelial progenitor cell senescence through induction of oxidative stress. J Hypertens 2005; 23: 97-104.

23 Imanishi T, Moriwaki C, Hano T, Nishio I. Endothelial progenitor cell senescence is accelerated in both experimental hypertensive rats and patients with essential hypertension. J Hypertens 2005; 23: 1831-1837.

24 Yao EH, Fukuda N, Matsumoto T, Kobayashi N, Katakawa M, Yamamoto C, Tsunemi A, Suzuki R, Ueno T, Matsumoto K. Losartan improves the impaired function of endothelial progenitor cells in hypertension via an antioxidant effect. Hypertens Res 2007; 30: 1119-1128.

25 Min TQ, Zhu CJ, Xiang WX, Hui ZJ, Peng SY. Improvement in endothelial progenitor cells from peripheral blood by ramipril therapy in patients with stable coronary artery disease. Cardiovasc Drugs Ther 2004; 18: 203-209.

26 Sedeek M, Hebert RL, Kennedy CR, Burns KD, Touyz RM. Molecular mechanisms of hypertension: role of Nox family NADPH oxidases. Curr Opin Nephrol Hypertens 2009; 18: $122-127$

27 Coleman A, Freeman P, Steel S, Shennan A. Validation of the Omron 705IT (HEM-759E) oscillometric blood pressure monitoring device according to the British Hypertension Society protocol. Blood Press Monit 2006; 11: 27-32.

28 Riggio S, Mandraffino G, Sardo MA, ludicello R, Camarda N, Imbalzano E, Alibrandi A, Saitta C, Carerj S, Arrigo T, Saitta A. Pulse wave velocity and augmentation index, but not intima-media thickness, are early indicators of vascular damage in hypercholesterolemic children. Eur J Clin Invest 2010; 40: 250-257.

29 Fadini GP, Pagano C, Baesso I, Kotsafti O, Doro D, de Kreutzenberg SV, Avogaro A, Agostini C, Dorigo MT. Reduced endothelial progenitor cells and brachial artery flowmediated dilation as evidence of endothelial dysfunction in ocular hypertension and primary open-angle glaucoma. Acta Ophthalmol 2010; 88: 135-141.

30 Buemi M, Allegra A, D'Anna R, Coppolino G, Crasci E, Giordano D, Loddo S, Cucinotta $M$, Musolino C, Teti D. Concentration of circulating endothelial progenitor cells (EPC) in normal pregnancy and in pregnant women with diabetes and hypertension. Am J Obstet Gynecol 2007; 196: 68.e1-68.e6.

31 Nolan T, Hands RE, Bustin SA. Quantification of mRNA using real-time RT-PCR. Nat Protoc 2006; 1: 1559-1582. 
32 Ferreira-Cravo M, Piedras FR, Moraes TB, Ferreira JL, de Freitas DP, Machado MD, Geracitano LA, Monserrat JM. Antioxidant responses and reactive oxygen species generation in different body regions of the estuarine polychaeta Laeonereis acuta (Nereididae). Chemosphere 2007; 66: 1367-1374.

33 Pesarin F. On a nonparametric combination method for dependent permutation tests with applications. Psychother Psychosom 1990; 54: 172-179.

34 Qian C, Schoemaker RG, van Gilst WH, Roks AJ. The role of the renin-angiotensinaldosterone system in cardiovascular progenitor cell function. Clin Sci (Lond) 2009; 116: 301-314.

35 Tousoulis D, Andreou I, Antoniades C, Tentolouris C, Stefanadis C. Role of inflammation and oxidative stress in endothelial progenitor cell function and mobilization: therapeutic implications for cardiovascular diseases. Atherosclerosis 2008; 201: 236-247.

36 Werner N, Kosiol S, Schiegl T, Ahlers P, Walenta K, Link A, Bohm M, Nickenig G. Circulating endothelial progenitor cells and cardiovascular outcomes. $N$ Engl J Med 2005; 353: 999-1007.

37 Vasa M, Fichtlscherer S, Aicher A, Adler K, Urbich C, Martin H, Zeiher AM, Dimmeler S. Number and migratory activity of circulating endothelial progenitor cells inversely correlate with risk factors for coronary artery disease. Circ Res 2001; 89: E1-E7.
38 Delva P, Degan M, Vallerio P, Arosio E, Minuz P, Amen G, Di Chio M, Lechi A. Endothelial progenitor cells in patients with essential hypertension. J Hypertens 2007; 25: 127-132.

39 Fadini GP, Baesso I, Albiero M, Sartore S, Agostini C, Avogaro A. Technical notes on endothelial progenitor cells: ways to escape from the knowledge plateau. Atherosclerosis 2008; 197: 496-503.

40 Hirschi KK, Ingram DA, Yoder MC. Assessing identity, phenotype, and fate of endothelial progenitor cells. Arterioscler Thromb Vasc Biol 2008; 28: 1584-1595.

41 Urao N, Inomata H, Razvi M, Kim HW, Wary K, McKinney R, Fukai T, Ushio-Fukai M. Role of nox2-based NADPH oxidase in bone marrow and progenitor cell function involved in neovascularization induced by hindlimb ischemia. Circ Res 2008; 103: 212-220.

42 Virdis A, Neves MF, Amiri F, Touyz RM, Schiffrin EL. Role of NAD(P)H oxidase on vascular alterations in angiotensin II-infused mice. J Hypertens 2004; 22. 535-542.

43 Landmesser U, Cai H, Dikalov S, McCann L, Hwang J, Jo H, Holland SM, Harrison DG. Role of p47(phox) in vascular oxidative stress and hypertension caused by angiotensin II. Hypertension 2002; 40: 511-515. 